\title{
Isolation and Characterization of the Major Outer Membrane Protein (OMP) of Pasteurella multocida Serotype B:2
}

\author{
Joycee Jogi*, Anju Nayak, P.C. Shukla, Amita Dubey, Ranvijay Singh, \\ Ajay Rai and Poonam Shakya
}
Department of Veterinary Microbiology, College of Veterinary Science \& A.H., NDVSU, Jabalpur, India

*Corresponding author

\begin{tabular}{l} 
Ke y w o r d s \\
$\begin{array}{l}\text { Pasteurella } \\
\text { multocida, SDS- } \\
\text { PAGE, Outer } \\
\text { membrane protein }\end{array}$ \\
\hline Article Info \\
\hline $\begin{array}{l}\text { Accepted: } \\
07 \text { October } 2019 \\
\text { Available Online: } \\
10 \text { November } 2019\end{array}$ \\
\hline
\end{tabular}

A B S T R A C T
Outer membrane proteins (OMPs) play a significant role in the pathogenesis of Pasteurellosis. Outer membrane proteins of P. multocida are reported to be immunogenic and protective. OMPs of Pasteurella multocida ( $P$. multocida) B:2 vaccine strain P52 was characterized by using sodium dodecyl sulphate polyacrylamide gel electrophoresis (SDS-PAGE) technique. The $P$. multocida P52 OMP demonstrated the presence of six OMP bands. The major bands were of 20, 34, 48, 72, 89 and $91 \mathrm{kDa}$. Potential immunogens of P. multocida P52 were identified by electroblot immunoassay. Immunoblotting was performed using the hyperimmune serum raised against the whole cell antigen. Polypeptides separated on $12 \%$ SDS-PAGE were transferred to nitrocellulose membrane by semi-dry system. Presence of three polypeptides of 34,72 and $91 \mathrm{kD}$ size was reported showing reaction with antiserum. A single band of $34 \mathrm{kDa}$ in SDSPAGE was evident and was confirmed by western blot analysis.

\section{Introduction}

Pasteurella multocida is a gram negative coccobacilli and found as a commensal of digestive and respiratory tract of warm blooded animals. It causes diseases in animals (bovines, porcines, rabbits and poultry) immune suppressed by stresses such as viral infections, heat, cold or humidity with aerosol transmission of infection between animals. Haemorrhagic Septicaemia (HS) is an acute, fatal septicaemic disease of cattle and buffaloes caused by the bacterium Pasteurella multocida and occur as a catastrophic epizootic in many Asian and African countries resulting in high mortality and morbidity. Serotypes B:2 and E:2 of P. multocida are associated with HS in cattle and buffaloes in 
Asia and Central Africa, respectively. In India, it is estimated to cause economic losses of more than 10 million rupees annually (Venkataramanan et al., 2005) thus it is responsible for maximum mortality of livestock in the country (National Animal Diseases Referral Expert System (NADRES) of the Project Directorate on Animal Disease Monitoring and Surveillance, 2012).

The pathogenic potential of $P$. multocida in vertebrate animals was recognized over a century ago and infections are broadly termed as Pasteurelloses. P. multocida infects a wide range of animal hosts causing specific infections that manifest differently. Indeed, $P$. multocida has a broad host range, but this peculiar property is poorly understood. Potential virulence factors of $P$. multocida have recently been reviewed (Hunt et al., 2000; Christensen and Bisgaard, 2000; Harper et al., 2006) but no host-specific factors have been identified till yet. The pathogenesis of the disease is a result of complex interactions between host factors (species, age, immune status) and specific bacterial virulence factors which includes LPS, capsule, adhesin, outer membrane etc. (Boyce et al., 2012).

The outer membrane proteins (OMPs) of Gram negative bacteria play essential roles in host-pathogen interactions and in disease processes. Outer membrane proteins of $P$. multocida play a significant role in the pathogenesis of pasteurellosis and have been identified as potent immunogens (Singh et al., 2011). Outer membrane proteins of $P$. multocida have been recognized as immunodominant antigens and are thought to be responsible for cross protective immunity, since lipopolysaccharides (LPS) alone induces only partial protection against pasteurellosis in mice (Ryu and Kim, 2000). The immunogenicity of selected outer membrane proteins of $P$. multocida was demonstrated in rabbits, calves and chickens (Zhang et al.,
1994). The outer membrane proteins also have protective role against HS. About 15 to 20 band profiles of outer membrane proteins of molecular weight ranging from 16 to $90 \mathrm{kDa}$ have been documented in all strains of $P$. multocida (Tomer et al., 2002) and OMPs of 39,46 and 82 to $87 \mathrm{kDa}$ have been identified in all isolates. Outer membrane proteins are important determinants of immunoprotection, hence can serve as vaccine candidates against HS.

The current focus on developing a newer vaccine has identified membrane antigens as potential immunogens in Gram negative bacteria (Zhou et al., 2009). OMP of $P$. multocida have been implicated as protective immunogen. $P$. multocida expresses both heat modifiable protein (OmpA) and porin $(\mathrm{OmpH}) . \mathrm{OmpH}$ possesses both specific and cross-reacting epitopes which are abundantly expressed on the bacterial surface, $\mathrm{OmpH}$ is a surface-exposed conserved immunodominant porin that is detected in $100 \%$ of bovine isolates and it has been viewed as a potential vaccine candidate (Dabo et al., 2008). It contains a high proportion of antiparallel $\beta$ chains, giving it a barrel shape.

The present work shows the OMP profiling of standard vaccine strain P52 by sodium dodecyl polyacrylamide gel electrophoresis (SDS-PAGE). Further immunodominant proteins were identified by western blotting.

\section{Materials and Methods}

For the present study the ampoule containing culture of $P$. multocida serotype B:2 (strain P52) was streaked directly on streaked on blood agar plate for isolation of a single colony and incubated overnight at $37^{\circ} \mathrm{C}$. The colony characters were observed on blood agar plate. Approximately $0.5 \mathrm{ml}$ of $10^{-5}$ dilution of $18 \mathrm{hrs}$. old culture of P52 was injected intraperitoneally into three healthy 
mice. All of them died within 36-38 hrs of inoculation. The organisms were reisolated in pure culture from heart blood and spleen of the dead animals.

The purity and identity of the culture was tested by morphological, cultural and biochemical examinations. The biochemical tests were carried out as per the standard protocols described by Cowan and Steel (1970).

Slides were prepared by picking single colony and the air dried heat fixed smear of the culture was then stained with Gram's stain. The blood smear from heart blood of experimentally infected mice stained by Leishman stain. The smears were observed to study the morphology of bacteria under oil immersion microscope.

The isolate was streaked onto blood agar and MacConkey agar plate and incubated overnight at $37^{\circ} \mathrm{C}$. The biochemical tests such as indole, methyl red, Voges-Proskauer, catalase, oxidase and nitrate reduction test were performed with $P$. multocida isolate.

Then, the isolate was also subjected to sugar fermentation test using glucose, fructose, galactose, maltose, mannitol, sucrose, salicin, raffinose, inositol and rhamnose.

\section{Isolation of whole cell bacterial proteins}

Single colony of bacterial culture was inoculated in $1 \mathrm{ml}$ of broth and grown overnight. One $\mathrm{ml}$ from overnight grown culture was inoculated in 1 litre of broth and again grown for 12 hrs. Culture was centrifuged at $10,000 \mathrm{rpm}$ for $10 \mathrm{~min}$ and pellet was washed thrice in PBS. Pellet were then suspended in $10 \mathrm{mM}$ HEPES buffer and sonicated for $10 \mathrm{~min}$ in ice. Cell suspension was centrifuged for $30 \mathrm{~min}$ at $10,000 \mathrm{X} \mathrm{g}$. The clear supernatant was collected and filtered through $0.45 \mu \mathrm{m}$ filter paper. The filtrate was used as sonicated antigen for raising hyperimmune serum. Protein concentration was estimated by Nano drop spectrophotometer.

\section{Purification of outer membrane proteins}

For the purification of outer membrane protein (OMPs) sonicated antigen was centrifuged at $1,00,000 \mathrm{x} \mathrm{g}$ for $1 \mathrm{hr}$. at $4^{\circ} \mathrm{C}$ in an ultracentrifuge. The pellet obtained were resuspended in $2 \mathrm{ml}$ of $2 \%(\mathrm{w} / \mathrm{v})$ sodium lauryl sarcosine in $10 \mathrm{mM}$ HEPES buffer $(\mathrm{pH}$ 7.4) and incubated at room temperature for 1 $\mathrm{hr}$. The mixture was centrifuged at 1,00,000 $\mathrm{x}$ $\mathrm{g}$ for $1 \mathrm{hr}$. at $4^{\circ} \mathrm{C}$ and pellet were washed twice with distilled water. The pellet containing purified OMPs were dissolved in PBS. Obtained proteins (OMPs) were used for analysis of polypeptides and immunoblotting (Choi-Kim et al., 1991).

\section{Sodium dodecyl sulphate-polyacrylamide} gel electrophoresis (SDS-PAGE)

Outer membrane proteins of $P$. multocida P52 were analyzed by SDS-PAGE using the method of Laemmli (1970). The vertical slab gel electrophoresis apparatus was used for performing SDS-PAGE by discontinuous buffer system using $12 \%$ resolving gel and $4 \%$ stacking gel. The vertical slab gel unit was assembled in casting mode with spacers. The solution was mixed well and poured into the sandwich to a level of $4 \mathrm{~cm}$ from the top, then a layer isopropanol was gently added to form the uniform gel surface after polymerization. The layer was poured off. Stacking gel was prepared and overlayed on the resolving gel. After putting the comb into the sandwich, the gel was allowed to polymerize. Fifty $\mu$ l of the sample was mixed with equal volume of $2 \mathrm{X}$ sample buffer and boiled for $5 \mathrm{~min}$ in a water bath. The comb was slowly removed from the gel after polymerization. The wells were filled with electrode buffer. The samples and protein 
marker were loaded in each well. The lower and upper chambers of the tank were also filled with electrode buffer. The electrophoresis unit was connected to the power pack and the gel was run initially at $80 \mathrm{~V}$ and then at $120 \mathrm{~V}$ till the tracking dye reached to the bottom of the gel. The gel was stained with Coomassie brilliant blue for two hrs. Later, the gel was destained in destaining solution with intermittant shaking. Finally gel was rinsed in distilled water and scanned. After destaining the molecular weight of polypeptides were determined by the molecular weight analysis tool of the gel documentation system. The molecular weight of protein was determined by comparing with standard protein molecular weight marker.

Identification of immunogenic proteins by western blotting

Polypeptides separated on 12\% SDS-PAGE using discontinuous buffer system were transferred on nitrocellulose membrane by semi-dry method of electroblotting as per the method of Towbin et al., (1979) with minor modifications. Five sheets of thick Whatman filter paper were soaked in transfer buffer and placed on centre of graphite anode electrode plate. The distilled water soaked NCM (Nitrocellulose membrane) was then placed on the top of filter papers. The gel was placed on the membrane followed by stacking of five sheets of filter papers soaked in transfer buffer. The assembled transfer stack was covered with cathode plate and current of 0.8 $\mathrm{mA} / \mathrm{cm}^{2}$ was applied for one hr. The electrophoretic blot was kept in blocking buffer overnight at $4^{\circ} \mathrm{C}$. After washing with wash buffer four times for 5 minutes each, the membrane was incubated at $37^{\circ} \mathrm{C}$ for one hr. with hyperimmune serum against whole cell antigen diluted 1:50 in blocking buffer. After washing 4 times with washing buffer each for $5 \mathrm{~min}$, the blot was again incubated at $37^{\circ} \mathrm{C}$ for $1 \mathrm{hr}$. with anti- rabbit horseradish peroxidase conjugate at a dilution of 1:2000 in blocking buffer. The blot as described above, was transferred to freshly prepared $50 \mathrm{ml}$ of substrate solution containing diaminobenzidine tetrahydrochloride and $6 \mu \mathrm{l}$ of $30 \%(\mathrm{v} / \mathrm{v})$ hydrogen peroxide for few min. The reaction was stopped by washing with distilled water. After drying, the membrane was stored in a dark place.

\section{Purification of $34 \mathrm{kDa}$ outer membrane protein and its confirmation by western blot}

For purification of $\mathrm{OmpH}$, the band corresponding to $34 \mathrm{kDa}$ was excised from the preparative gel, of $3 \mathrm{~mm}$ thickness, and incubated in a rotary shaker at $30^{\circ} \mathrm{C}$ overnight in one ml elution buffer $(50 \mathrm{mM}$ Tris- $\mathrm{HCl}$, $150 \mathrm{mM} \mathrm{NaCl}$ and $0.1 \mathrm{mM}$ EDTA; $\mathrm{pH}$ 7.5). Centrifugation was done at 7,000 $\mathrm{g}$ for $10 \mathrm{~min}$ to obtain the supernatant as OmpH. The protein was tested for the presence of single band in SDS-PAGE.

\section{Results and Discussion}

Culture of $P$. multocida P52 was revived on Brain Heart Infusion (BHI) broth and blood agar. Characteristic non-haemolytic colonies were obtained which were gram-negative coccobacilli.

\section{Pathogenicity test of the organism}

Mice were inoculated intraperitoneally with $0.5 \mathrm{ml}$ of $10^{-5}$ dilution of $18 \mathrm{hrs}$. old broth culture of $P$. multocida P52 and they were found dead within 24-48 hours. The reisolated colonies showed characteristic of $P$. multocida.

\section{Characterization of culture}

P. multocida produced small, smooth, circular, glistening and dew drop like colonies without haemolysis on blood agar (BA) plate on 
incubation at $37^{\circ} \mathrm{C}$ for $24 \mathrm{hrs}$. The colonies were found to be watery, discrete and translucent with a characteristics odour of the culture (Fig. 1). On microscopic examination of stained smears, the isolate was found to be Gram-negative cocco-bacilli, arranged singly or in pairs. The bipolar reaction exhibited by the isolates following methylene blue staining was an indication of P. multocida. No motility was observed in stab culture in semisolid agar at $37^{\circ} \mathrm{C}$. There was no growth on MacConkey's lactose agar (MLA). Biochemical characterization revealed that $P$. multocida fermented glucose, fructose, galactose, maltose, mannitol and sucrose but salicin, raffinose, inositol and rhamnose were not fermented. Indole production along with catalase and oxidase production was also shown by the purified organism.

Rajkhowa et al., (2012) and El-Jakee et al., (2016) studied cultural, morphological and biochemical characteristics of $P$. multocida. The organism is Gram-negative short ovoid rod with bipolar staining characteristics, nonhaemolytic, aerobic to facultative anaerobic and produces indole, oxidase, catalase, ferment carbohydrates with slight gas production and failed to grow on MacConkey agar. Similar type of studies were also conducted by Verma (1991) and De Alwis (1996). Chawak et al., (2000) reported the biochemical characterization of $P$. multocida of avian origin and they were uniform in fermentation of fructose, mannitol, sucrose and glucose. Yadav et al., (2016) isolated $P$. multocida $\mathrm{B}: 2$ were from buffaloes and cattle. The isolates were found genetically distinct from standard Pasteurella multocida strain P52 (Vaccine strain of India).Two isolates shared same profile while all other isolates shown different profiles. This study provides a clear evidence of presence of more than one isolate in single outbreak of $\mathrm{HS}$ and also provide indication of high genetic variation among field isolates of Pasteurella sp. and may be the reason of vaccine failure and outbreaks. Likewise studies conducted by Jogi and Shakya (2013), also revealed that the field strain is different from the vaccine strain which may be a possible reason for outbreaks.

\section{Purification of outer membrane proteins}

The $P$. multocida P52 outer membrane proteins were obtained by the method as described by Choi-kim et al., (1991), demonstrated the presence of six OMP bands in P. multocida P52. The molecular weights of the major polypeptide bands were in the range of 20 to $91 \mathrm{kDa}$. The major bands were of 20 , 34, 48, 72, 89 and $91 \mathrm{kDa}$ (Fig. 2).

Outer membrane proteins of $P$. multocida are reported to be immunogenic and protective (Srivastava, 1998, Basagoudanavar et al., 2006 and Joshi et al., 2013). Some of the major outer membrane proteins like porins are reported to be highly immunogenic. These are pore forming outer membrane proteins and possess beta barrel structure having extracellular, transmembrane and intracellular domain. They are conserved in gram-negative bacteria showing high homology in primary amino acid sequence and secondary structure (Jeanteur et al., 1991 and Dabo et al., 2008). They form large channels allowing the diffusion of hydrophilic molecules into periplasmic space. They are strong immunogen and have been demonstrated to induce protective immunity in animal models against gram-negative bacterial infections (Luo et al., 1999, Tan et al., 2010 and Joshi et al., 2013).

The outer membrane proteins of $P$. multocida P52 were isolated by the method described by Choi-Kim et al., (1991). The organism was disrupted by sonication and large particles were removed by centrifugation at low speed. The OMPs were separated into detergent insoluble and detergent soluble fractions. 
Sonicated antigen was used to induce antibody production. Antiserum raised against whole cell protein was used for western blot analysis. It was possible to identify immunodominant outer membrane protein(s) and recombinant clones containing specific OMP gene.

Omp34 belongs to beta-barrel protein super family. The outer membrane of Gram-negative bacteria acts as a molecular filter for hydrophilic compounds. Proteins known as porins are responsible for the molecular sieve properties of the outer membrane. Porin is a major antigenic outer membrane protein of $P$. multocida and has high immunogenicity in antibody production (Lee et al., 2007).

SDS-PAGE analysis of OMP preparation of $P$. multocida $\mathrm{P} 52$ strain revealed the presence of six polypeptide bands. The molecular weight of these polypeptides varied between $20 \mathrm{kDa}$ to $91 \mathrm{kDa}$.

With little difference, Pati et al., (1996) reported ten polypeptides bands of molecular weight 25 to $88 \mathrm{kDa}$ of the same preparation. Kedrak and Opacka (2002) reported protein bands of 22 to $86 \mathrm{kDa}$ in the OMP profiles of bovine strains (serotype B:2). The polypeptides of 31,34 and $37 \mathrm{kDa}$ molecular weights gave prominent bands on SDS-PAGE indicating that the same were synthesized in abundance corroborating the observations made by Tomer et al., (2002).

The results of our study are in close accordance with Munir et al., (2007) they characterized outer membrane protein of $P$. multocida and obtained total of 6 polypeptides ranging from $15 \mathrm{kDa}$ to $91 \mathrm{kDa}$ and Ataei et al., (2009) investigated the immunogenic outer membrane proteins in a wild type $P$. multocida serotype B:2, five proteins viz., 50, $37,30,26$ and $16 \mathrm{kDa}$ were found in the sonicated cell extract. Present results are somewhat different with the results of other workers. Wasnik (1998) and Tomer et al., (2002) detected 13 and 20 polypeptidess bands respectively, in profiles of outer membrane proteins. Jain et al., (2005) revealed the presence of 11 protein fractions with two major OMPs of 32 and $35 \mathrm{kDa}$ in capsular type $\mathrm{B}$ isolates.

Arora et al., (2007) have reported a homogenous outer membrane profile of 17 different $P$. multocida isolates of bovine origin comprising 23 polypeptides ranging in $\mathrm{MW}$ from 13 to $94 \mathrm{kDa}$. On the basis of band thickness and stain intensity $32 \mathrm{kDa}$ protein appeared to be the major protein followed by 25 and $28 \mathrm{kDa}$.

Apart from this, other significant protein bands observed were 13, 34, 44.5, 46, 80 and $84 \mathrm{kDa}$. Yadav (2008) revealed the presence of eight polypeptide bands. The molecular weight of these polypeptides varied between $16 \mathrm{kDa}$ to $97 \mathrm{kDa}$ comprising of major protein of $34 \mathrm{kDa}$ and $87 \mathrm{kDa}$. Joshi et al., (2013) also reported that $34 \mathrm{kDa}$ protein was immunodominant.

They also considered that $34 \mathrm{kDa}$ protein band represented a type specific marker for the Asian HS isolates so it might be act as a candidate antigen for a subunit HS vaccine and can be exploited in immunodiagnosis of HS.

\section{Identification of immunogenic proteins by western blotting}

Potential immunogens of $P$. multocida P52 were identified by electroblot immunoassay. Immunoblotting was performed using the hyperimmune serum raised against the whole cell antigen in order to detect immunogenic proteins in outer membrane proteins. Polypeptides separated on 12\% SDS-PAGE were transferred to nitrocellulose membrane by semi-dry system. 
Fig.1 Small, smooth, circular, glistening and dew drop like nonhaemolytic colonies on blood agar after incubation at $37^{\circ} \mathrm{C}$ for 24 hours

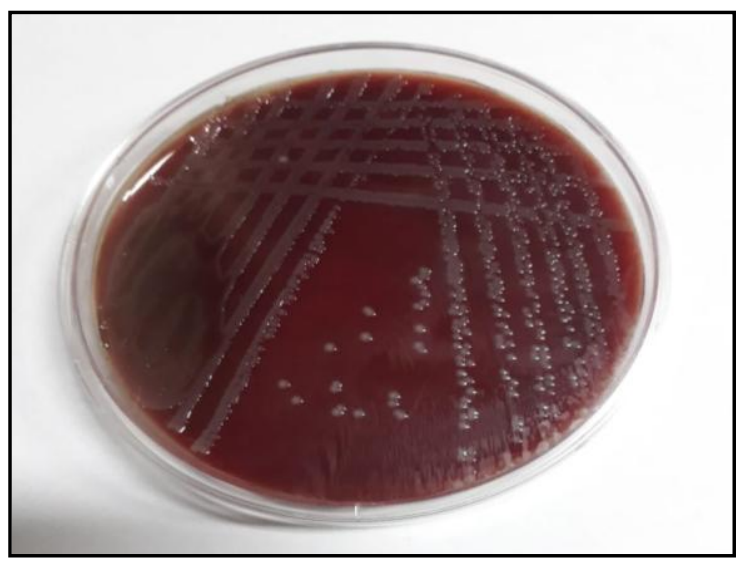

Fig.2 SDS-PAGE of outer membrane protein of P. multocida (P52)

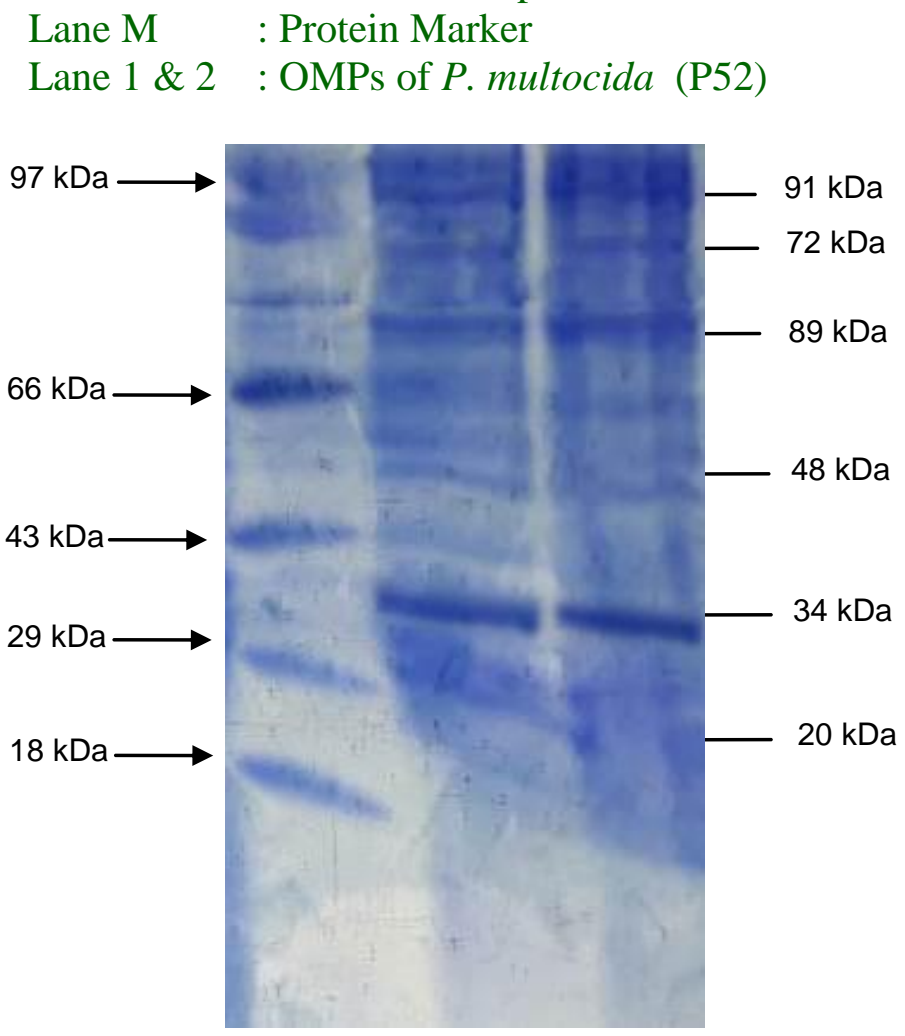


Fig.3 Western blot of Purified OMP of P. multocida (P52)

Lane M : Protein Marker

Lane $1 \& 2 \quad: 34 \mathrm{kDa}$ purified OMP of P. multocida (P52)

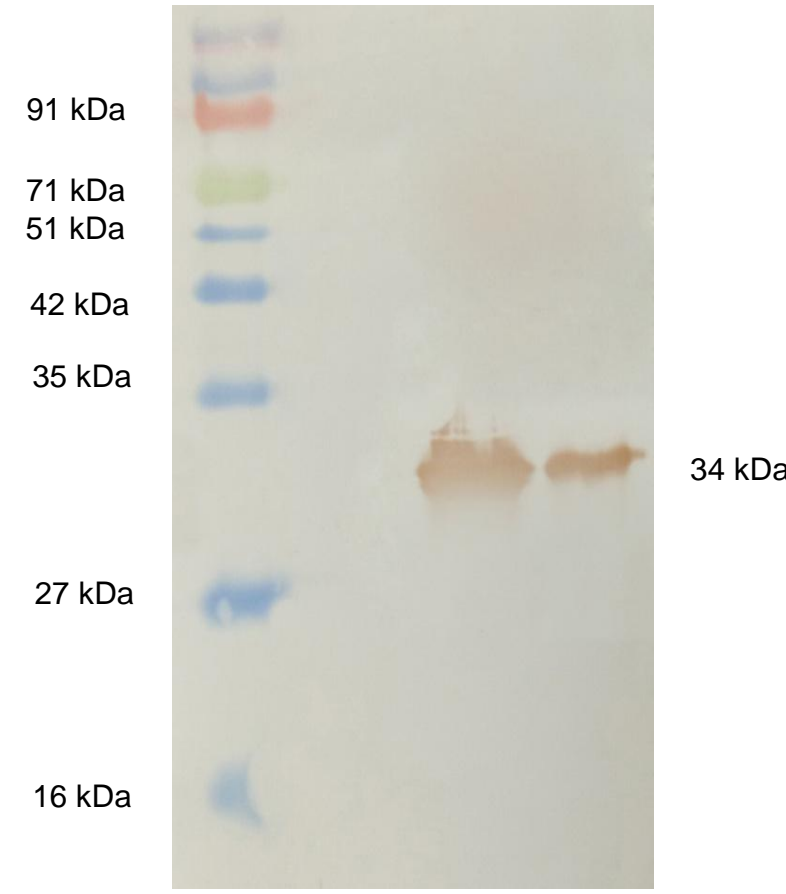

Presence of three polypeptides of 34,72 and $91 \mathrm{kDa}$ size was reported showing reaction with antiserum. The results of western blot profiles of major immunogens indicated that all the major protein bands appeared immunogenic; however $34 \mathrm{kDa}$ protein was found to be most immunodominant among them. In the present study, out of six immunodominant outer membrane proteins, three polypeptides of 34,72 and $91 \mathrm{kDa}$ molecular weights were identified. The results differed little from those reported by Pati et al., (1996) who encountered faint signals of only three outer membrane proteins of 44,37 , and $33 \mathrm{kDa}$ reacting to hyperimmune sera. According to Arora et al., (2007), $32 \mathrm{kDa}$ protein band was found to be immunodominant along with $25 \mathrm{kDa}$ in all the $P$. multocida isolates of bovine origin.

The original objective of this study was to isolate and characterize the ompH gene encoding immunopotent outer membrane protein of $P$. multocida B:2 P52 strain. Although, about six (polypeptide) bands of outer membrane proteins were resolved on SDS-PAGE, all these peptides were not equally immunopotent and reacted differently on immunoblotting. With previous observations, the $34 \mathrm{kDa}$ outer membrane protein was found to be potential immunogen. It was found to react strongly on western blot with antisera raised against sonicated antigen. The results strengthened the studies performed by Yadav (2008) and Joshi et al., (2013) that an immunodominant antigen and might serve as potent immunogen in vaccine preparation. Protein of $34 \mathrm{kDa}$ was found to be immunodominant antigen in our study.

\section{Purification of $34 \mathrm{kDa}$ outer membrane protein and its confirmation by western blot}

The band corresponding to $34 \mathrm{kDa}$ was excised from the gel and incubated in a rotary shaker 
at $30^{\circ} \mathrm{C}$ overnight in one ml elution buffer. A single band of $34 \mathrm{kDa}$ in SDS-PAGE was evident and was confirmed by western blot analysis (Fig. 3).

\section{Acknowledgements}

The authors acknowledge The Dean, College of Veterinary science \& A. H. for providing necessary facilities to carry out the research. The authors highly acknowledge the faculty of IISER, Bhopal for helping to carry out the current research.

\section{References}

Anonymous. 2012. Status of Haemorrhagic Septicaemia in India. PD_ADMAS/ technical bulletin / 11 / 2012.

Arora, A.K., Jand, S.K., Sandhu, K.S. and Oberoi, M.S. 2007. Outer membrane profiles of Pasteurella multocida isolate of bovine origin. The Indian Journal of Animal Sciences, 77(8): 663-666.

Ataei, S., Burchmore, R., Christopher, H.J., Finucane, A., Patron, R. and Coote, J.G. 2009. Identification of immunogenic proteins associated with protection against Haemorrhagic septicaemia after vaccination of calves with a live-attenuated aroA derivative of Pasteurella multocida B:2. Research in Veterinary Science, 87(02): 207-210.

Basagoudanavar, S.H., Singh, D.K. and Varshney, B.C. 2006. Immunization with outer membrane proteins of Pasteurella multocida 6:B provides protection in mice. Journal of Veterinary Medicine, Physiology, Pathology, Clinical Medicine, 53: 524530.

Boyce, J.D., Seemann, T., Adler, B. and Harper, M. 2012. Pathogenomics of Pasteurella multocida. Current topics in Microbiology and Immunology, 361: 23-38.

Chawak, M.M., Verma, K.C., Kataria, J.M. and Kumar, A.A. 2000. Characterization of indigenous isolates of avian Pasteurella multocida. Indian Journal of Comparative Microbiology, Immunology and Infectious Diseases, 21: 111-114.

Choi-Kim, K., Maheswaran, S.K., Felice, L.J. and Molitor, T.W. 1991. Relationship between the iron regulated outer membrane proteins and the outer membrane proteins of in vivo grown Pasteurella multocida. Veterinary Microbiology, 28: 75-92.

Christensen, J.P. and Bisgaard, M. 2000. Fowl cholera. Revue scientifique et technique / Office international des épizooties, 19: 626-637.

Cowan, S.T. and Steel, K.J. 1970. Manual for the Identification of Medical Bacteria, Cambridge: Cambridge University Press.

Dabo, S.M., Confer, A., Montelongoa, M., Yorka, P. and Wyckoff, J.H. 2008. Vaccination with Pasteurella multocida recombinant OmpA induces strong but non-protective and deleterious Th2-type immune response in mice. Vaccine, 26: 4345-4351.

De Alwis, M.C.L. 1996. Haemorrhagic Septicaemia: clinical and epidemiological features of the disease. In: Proceedings of International Workshop on Diagnosis and Control of HS Bali, Indonesia, May 28- 30.

El-Jakee, J.K., Ali, S.S., El-Shafii, S.A., Hessain, A.M., Al-Arfaj, A.A. and Mohamed, M.I. 2016. Comparative studies for serodiagnosis of haemorrhagic septicaemia in cattle sera. Saudi Journal of Biological Sciences, 23(1): 48-53.

Harper, M., Boyce, J.D. and Adler, B. 2006. 
Pasteurella multocida pathogenesis: 125 years after Pasteur. FEMS Microbiology Letters, 265 (1): 1-10.

Hunt, M.L., Adler, B. and Townsend, K.M. 2000. The molecular biology of Pasteurella multocida. Veterinary Microbiology, 72: 3-25.

Jain, A., Roy, A., Rank, D.N., Joshi, C.G. and Purohit, J.H. 2005. Characterization of Pasteurella multocida by their outer membrane profile. Indian Journal of Comparative Microbiology, Immunology and Infectious Disease, 26(1): 63-65.

Jeanteur, D., Lakey, J.H. and Pattus, F. 1991. The bacterial porin superfamily: sequence alignment and structure prediction. Molecular Microbiology 5(9): 2153-2164.

Jogi, J., and Shakya, S. 2013. Characterization of Pasteurella multocida associated with outbreak in swine. Environment \& Ecology, 31(4A): 1848-1850.

Joshi, S., Tewari, K. and Singh, R. 2013. Comparative immunogenicity and protective efficacy of different preparations of Outer membrane proteins of $\mathrm{P}$. multocida $\mathrm{B}: 2$ in a mouse model. Veterinarski arhiv, 83 : 665-676.

Kedrak, A. and Opacka, B.B. 2002. Analysis of protein patterns of Pasteurella multocida strains isolated from poultry. Bulletin of the Veterinary Institute in Pulawy, 46: 149-155.

Laemmli, U.K. 1970. Cleavage of structural proteins during the assembly of the head of bacteriophage T4. Nature, 227(5259): 680-685.

Lee, J., Kim, Y.B. and Kwon, M. 2007. Outer membrane protein $\mathrm{H}$ for protective immunity against Pasteurella multocida. Journal of Microbiology, 45: 179-184.

Luo, Y., Zeng, Q., Glisson, J.R., Jackwood, M.W., Cheng, I.H. and Wang, C. 1999.
Sequence analysis of Pasteurella multocida major outer membrane protein $(\mathrm{OmpH})$ and application of synthetic peptides in vaccination of chickens against homologous strain challenge. Vaccine, 17: 821-831.

Munir, R., Shahwar, D., Farooq, U., Nawaz, I., Shahzad, I. and Khanum, A. 2007. Outer membrane protein profiling of Pasteurella multocida. Pakistan Veterinary Journal, 27(1): 1-4.

Pati, U.S., Srivastava, S.K., Roy, S.C. and More, T. 1996. Immunogenicity of outer membrane protein of Pasteurella multocida in buffalo calves. Veterinary Microbiology, 52: 301-311.

Rajkhowa, S., Shakuntala, I., Pegu, S.R., Das, R.K. and Das, A. 2012. Detection of Pasteurella multocida isolates from local pigs of India by polymerase chain reaction and their antibiogram. Tropical Animal Health and Production, 44 (7): 1497-1503.

Ryu, H. and Kim, C. 2000. Immunologic reactivity of a lipopolysaccharideprotein complex of type A Pasteurella multocida in mice. Journal of Veterinary Science, 1: 87-95.

Singh, R., Tewari, K., Packiriswamy, N., Marla, S. and Rao, V.D.P. 2011. Molecular characterization and computational analysis of the major outer membrane protein $(\mathrm{ompH})$ gene of Pasteurella multocida P52. Veterinarski arhiv, 81(2): 211-222.

Srivastava, S.K. 1998. Outer membrane protein of Pasteurella multocida serotype B:2 is immunogenic and antiphagocytic. Indian Journal of Experimental Biology, 36: 530-532.

Tan, H.Y., Nagoor, N.H. and Sekaran, S.D. 2010. Cloning, expression and protective capacity of $37 \mathrm{kDa}$ outer membrane protein gene $(\mathrm{ompH})$ of Pasteurella multocida serotype B:2. Tropical Biomedicine, 27(3): 430-441. 
Tomer, P., Chaturvedi, G.C., Minakshi., Malik, P. and Monga, D.P. 2002. Comparative analysis of the outer membrane profiles of isolates of the Pasteurella multocida (B:2) associated with Haemorrhagic Septicaemia. Veterinary Research Communications, 26(7): 513- 522.

Towbin, H., Staehelin, T. and Gordon, J. 1979. Electrophoretic transfer of proteins from polyacrylamide gels to nitrocellulose sheets: procedure and some applications. Proceedings of the National Academy of Sciences of the United States of America, 76(9): 43504354.

Venkataramanan, R., Bandyopadhyay, S.K. and Oberoi, M.S. 2005. Present status and strategies for the control of transboundary and other economically important animal diseases in India: A review. Indian Journal of Animal Sciences, 75: 456-464.

Verma N.D. 1991. Type B:2 P. multocida in an outbreak of primary swine pasteurellosis. Indian Journal of Animal Sciences, 61: 158-160.

Wasnik, R.V., Srivastava, S.K. and Paul, A. 2004. Cross protective efficacy of whole cell and outer membrane protein vaccines of $P$. multocida serotype B:2.
Indian Journal of Animal Sciences, 74(8): 805-809.

Yadav, A. 2008. Cloning and characterization of outer membrane proteins of Pasteurella multocida serotype B:2. Ph.D. thesis (Microbiology), Govind Ballabh Pant University of Agriculture and Technology, Uttarakhand, India.

Yadav, A., Sharma, A., Kumar, R., Rao, V.D.P. and Saxena, M.K. 2016. Molecular characterization Indian isolates of Pasteurella multocida isolated from Buffalo and Cattle in India. International Journal of Current Microbiology and Applied Sciences, 5(9): 302-310.

Zhang, H., Ainsworth, A. J. and Montgomery, R. D. 1994. Use of a $35.5 \mathrm{kDa}$ cell membrane composition of Pasteurella multocida and an anti-idiotype antibody to induce protective immunity in leghorn chickens. Veterinary Immunology and Immunopathology, 4: 89-100.

Zhou, M., Guo, Y., Zhao, J., Hu, Q., Hu, Y., Zhang, A., Chen, H. and Jin, M. 2009. Identification and characterization of novel immunogenic outer membrane proteins of Haemophilus parasuis serovar 5. Vaccine, 27: 5271-5277.

\section{How to cite this article:}

Joycee Jogi, Anju Nayak, P.C. Shukla, Amita Dubey, Ranvijay Singh, Ajay Rai and Poonam Shakya 2019. Isolation and Characterization of the Major Outer Membrane Protein (OMP) of Pasteurella multocida Serotype B:2. Int.J.Curr.Microbiol.App.Sci. 8(11): 474-484. doi: https://doi.org/10.20546/ijcmas.2019.811.058 